Chapter 14

\title{
Endoscopy in Pregnant Patients
}

\author{
Nurten Akyurek Savas \\ Additional information is available at the end of the chapter \\ http://dx.doi.org/10.5772/53242
}

\section{Introduction}

Although gastrointestinal endoscopy is generally safe, its safety must be separately analyzed during pregnancy. Though it is prudent to postpone the investigation to the third trimester or rather to the postpartum period; in certain clinical situations where therapeutic intervention is necessary, it offers a relatively safe alternative to radiologic or surgical intervention. There are a number of potential risks associated with endoscopy during pregnancy [1]:

1. Oversedation may cause maternal hypotension and hypoxia, which in turn may lead to fetal hypoxia, with potentially fatal consequences.

2. The fetus may be exposed to potentially teratogenic drugs and radiaton.

3. Care must be taken with maternal positioning to avoid inferior vena caval compression by the pregnant uterus, which can lead to decreased uterine blood flow and fetal hypoxia.

The American Society for Gastrointestinal Endoscopy (ASGE) guidelines [2] list the following general principles guiding endoscopy in pregnancy (Table1).

Fetal risks from endoscopic medications are minimized by avoiding FDA category D drugs, minimizing endoscopic medications, and anesthesiologist attendance at endoscopy. Esophagogastroduedenoscopy (EGD) seems to be relatively safe for the fetus and may be performed when strongly indicated during pregnancy. Flexible sigmoidoscopy during pregnancy also appears to be relatively safe for the fetus and may be performed when strongly indicated. Colonoscopy may be considered in pregnant patients during the second trimester if there is a strong indication. Data on colonoscopy during the other trimesters are limited. Therapeutic endoscopic retrograde cholangiopancreatography (ERCP) seems to be relatively safe during pregnancy and should be performed for strong indications (for example, complicated choledocholithiasis). Endoscopic safety precautions during pregnancy include the performance of endoscopy in hospital by an expert endoscopist and only when 
strongly indicated, deferral of endoscopy to the second trimester whenever possible, and obstetric consultation.

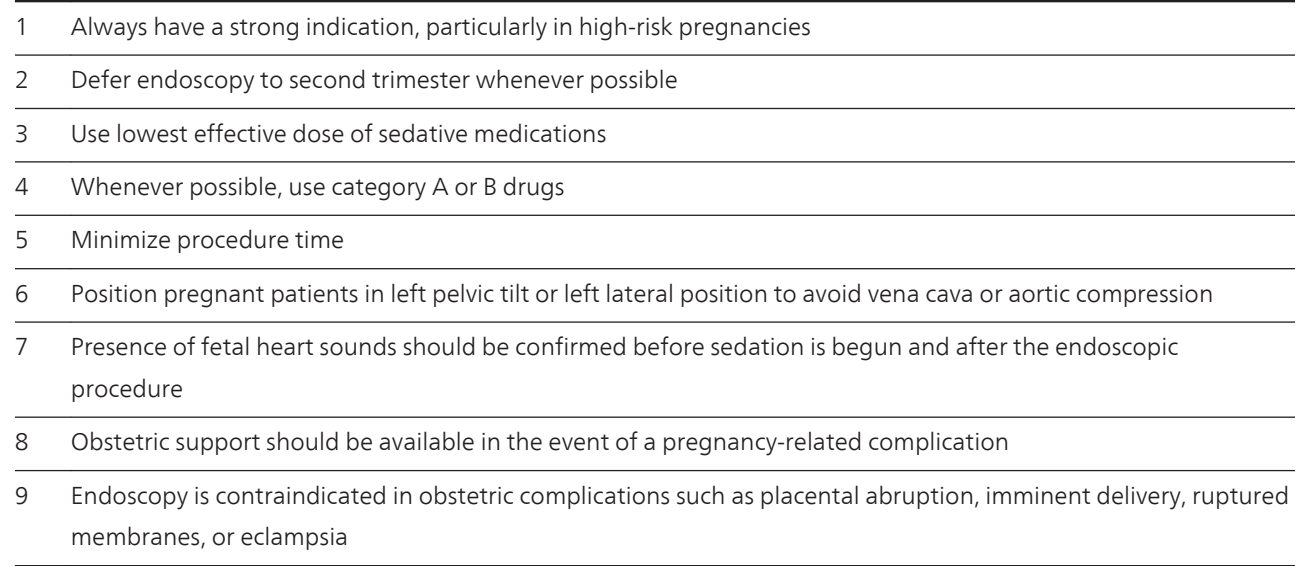

Table 1. General Principles guiding endoscopy in pregnancy (ASGE)

\section{Fetal safety of endoscopic medications}

One of the most important point in endoscopic procedures of pregnant patients is to avoid maternal hypoxia and hypotension which can cause placental hypoperfusion and potential fetal injury. Maternal oversedation with resulting hypoventilation or hypotension, or maternal positioning that might lead to inferior vena caval compression by the gravid uterus can lead to decreased uterine blood flow and fetal hypoxia. Other potential risks to the fetus include teratogenesis (both from medication given to the mother and radiation exposure from fluoroscopy) and premature birth [1-6]. To prevent hypoxia and hypotension during the intervention, pregnant patients should be positioned in the left lateral position, prompt intravenous hydration with normal saline or a similarly high osmolar solution should be made, use of analgesics and sedatives should be restricted if possible and in the case of necessity abortion of the endoscopic procedure should be considered $[5,6]$.

Sedation in pregnancy has always been a challenge to anesthesiologists. No anesthetic drug, inhaled anesthetics, or local anesthetic has been proven to be teratogenic in humans. A notable exception is benzodiazepine group, which has been linked to congenital anomalies. All agents that are administered during pregnancy must be used with caution and vigilence. It is clear that anesthetic effects on placental perfusion and the placental transfer of depressant drugs may influence the fetus [5,6,7].

During the endoscopic procedures in pregnant patients, anesthesiologic asistance is recommended in the first and third trimester because of the increaed risk of teratogenecity and the risk of premature labor, respectively [5]. 
The US Food and Drug Administration (FDA) lists 5 categories of drugs with regard to safety during pregnancy [8] (Table 2).

\begin{tabular}{|c|c|c|}
\hline Category & Risk & Description \\
\hline A & $\begin{array}{l}\text { Controlled } \\
\text { studies show } \\
\text { no risk }\end{array}$ & $\begin{array}{l}\text { Adequate, well-controlled studies in pregnant women have failed to demonstrate a risk } \\
\text { to the fetus in any trimester of pregnancy }\end{array}$ \\
\hline B & $\begin{array}{l}\text { No evidence of } \\
\text { risk in humans }\end{array}$ & $\begin{array}{l}\text { Adequate, well-controlled studies in pregnant women have not shown increased risk of } \\
\text { fetal abnormalities despite adverse findings in animals or, in the absence of adequate } \\
\text { human studies, animal studies show no fetal risk. The chance of fetal harm is remote, } \\
\text { but remains a possibility }\end{array}$ \\
\hline C & $\begin{array}{l}\text { Risk cannot be } \\
\text { ruled out }\end{array}$ & $\begin{array}{l}\text { Adequate, well-controlled human studies are lacking, and animal studies have shown a } \\
\text { risk to the fetus or are lacking as well. There is a chance of fetal harm if the drug is } \\
\text { administered during pregnancy, but the potential bene } \\
\text { fits may outweigh the potential risk }\end{array}$ \\
\hline D & $\begin{array}{l}\text { Positive } \\
\text { evidence of risk }\end{array}$ & $\begin{array}{l}\text { Studies in humans, or investigational or postmarketing data, have demonstrated fetal } \\
\text { < risk. Nevertheless, potential benefits from the use of the drug may outweigh the } \\
\text { potential risk. For example, the drug may be acceptable if needed in a life-threatening } \\
\text { situation or for serious disease for which safer drugs cannot be used or are ineffective }\end{array}$ \\
\hline$x$ & $\begin{array}{l}\text { Contraindicate } \\
\text { d in pregnancy }\end{array}$ & $\begin{array}{l}\text { Studies in animals or humans, or investigational or postmarketing reports, have } \\
\text { demonstrated positive evidence of fetal abnormalities or risk which clearly outweighs } \\
\text { any possible benefit to the patient }\end{array}$ \\
\hline
\end{tabular}

Table 2. FDA categorization of drug safety during pregnancy

This categorization indicates general risks based on four components: individual experimental studies on drug risk in laboratory animals, number and quality of experimental studies, individual clinical studies on drug risk in humans, and number and quality of clinical studies. FDA categorization is, nonetheless useful in clinical practice. Category A drugs are safe during pregnancy. Category B drugs may generally be used during pregnancy. Category C drugs may often be used if required during pregnancy. Category D drugs are relatively contraindicated, and when used should be administered with extreme caution. Category $X$ drugs are absolutely contraindicated during pregnancy [8].

There are no category A drugs used for endoscpy. For use during endoscopic procedures category B and, when necessary, category C drugs are recommended. Category D drugs may be used when benefits clearly outweigh the risks. These categories are of limited value for determining the safety of one- time use; therefore, consultation with an obstetrician regarding medication should be considered. For most procedures the level of sedation should be anxiolysis or moderate sedation. If deep sedation is necessary, it should be administered by an anesthesiologist [2].

Key data on safety of commonly used endoscopic medications are summarized in table 3. 


\begin{tabular}{|c|c|c|}
\hline Drug & $\begin{array}{l}\text { FDA category in } \\
\text { pregnancy }\end{array}$ & key points regarding drug safety \\
\hline \multicolumn{3}{|l|}{ Narcotics } \\
\hline Meperidine & $B$, but $D$ at term & $\begin{array}{l}\text { Repeated high dose and prolonged administration can cause respiratory depression } \\
\text { and seizures. }\end{array}$ \\
\hline Fentanyl & C & In low doses it is safe. \\
\hline Propofol & B & $\begin{array}{l}\text { Generally suggested to be used in difficult to sedate and complicated clinical } \\
\text { situations. }\end{array}$ \\
\hline \multicolumn{3}{|c|}{ General anesthetics } \\
\hline Ketamine & B & Human data is limited; animal data suggests prolonged usage is unsafe. \\
\hline \multicolumn{3}{|l|}{ Sedatives } \\
\hline Diazepam & $\mathrm{D}$ & $\begin{array}{l}\text { Some of congenital malformations and mental retardations are possibly associated } \\
\text { with diazepam usage so its usage is discouraged during pregnancy. }\end{array}$ \\
\hline Midazolam & $\mathrm{D}$ & $\begin{array}{l}\text { As a benzodiazepine member, its usage is restricted during pregnancy especially in } \\
\text { first trimester. }\end{array}$ \\
\hline \multicolumn{3}{|c|}{ Reversal agents } \\
\hline Naloxone & $\mathrm{B}$ & $\begin{array}{l}\text { It is probably safe and should be used only in respiratory depression, systemic } \\
\text { hypotension or unresponsiveness in a closely monitored pregnant after endoscopy. }\end{array}$ \\
\hline lumazenil & C & etal risks are largely unknown, it should be given in small doses carefully. \\
\hline
\end{tabular}

Table 3. Safety of anesthetics commonly used in gastrointestinal endoscopy

Meperidine, an opiate analgesic, was commonly used for gastrointestinal endoscopy in the general population, but has been replaced by short-acting analgesics due to theoretical concerns about toxicity, manifested as respiratory depression and seizures. Meperidine is rapidly transferred across the human placenta after intravenous administration, after that metabolized to normeperidine which has a long half-life. Repeated high dose and prolonged administration of meperidine can cause progressive accumulation of normeperidine, and produce toxic effects of maternal respiratory depression and seizures. Meperidine is rated a category B drug during pregnancy, but rated category D when used for prolonged periods $(>36 \mathrm{~h})$ at high doses at term. Meperidine use should be limited to $50-75 \mathrm{mg}$ during routine endoscopy during pregnancy $[4,5,9]$.

Fentanyl is a potent narcotic agonist with a rapid onset of action and a shorter patient recovery time than meperidine. It is an FDA category $\mathrm{C}$ drug during pregnancy. It appears safe when given in low doses $(<125 \mathrm{mg})$ in patients undergoing endoscopy during pregnancy $[2,4,5]$.

Benzodiazepines (diazepam and midazolam) are commonly administrated before gastrointestinal endoscopy to reduce anxiety, induce brief amnesia, and produce muscle relaxation. Prolonged use of diazepam during early pregnancy has been associated with cleft palate malformations $[4,11]$ but several large studies have not shown this association $[12,13]$. Some 
studies have raised possible associations between diazepam administration and mental retardation or neurologic defects,[14] cardiac defects [11] and Mobius syndrome (sixth and seventh nerve palsies) [15]. Diazepam is rated a category D drug during pregnancy, because of these potential associations its use during pregnancy is discouraged, particularly in the first trimester. Clinical data concerning fetal safety of midazolam are limited; however, the drug has not been associated with oral cleft palates. Administration of midazolam during labor has been reported to transiently depress neonatal neurobehavioral responsiveness $[16,17]$. Although rated a category D drug, since it has not been reported to be associated with congenital abnormalities, midazolam is the preferred benzodiazepine when meperidine is inadequate. Due to a similar mechanism of action as diazepam, midazolam use should be restricted during pregnancy, especially during the first trimester $[1,2,4,5]$.

Propofol is increasingly used for anesthesia at endoscopy in the general population. It is short -acting with a recovery period much shorter than with standard agents. However, as a result of a relatively narrow therapeutic index (defined as a ratio given by average toxic dose divided by average therapeutic dose) and the potential for respiratory depression which can cause respiratory arrest and even death if improperly monitored, it is generally administrated by anesthesiologists. Endoscopy socities have recommended the usage of this agent for difficult to sedate and complicated clinical situations. Propofol is rated a category B drug and it is considered relatively safe to use during pregnancy, although its safety during the first trimester is inadequately studied $[4,5,18]$.

Ketamine is useful for endoscopy in patients who are expected to experience insufficient sedation from propofol. Like propofol, ketamine has a rapid onset of action and a short duration of effect. Although rated a category B drug during pregnancy, ketamine carries the caveats that fetal safety during the first trimester is unstudied and unknown in humans, and an extremely high dose or prolonged administration of it during pregnancy may be unsafe $[4,19]$.

Naloxone, a rapidly acting narcotic antagonist, crossing the placenta within 2 minutes of intravenous administration, is occasionally administered during endoscopy to reverse narcotic overdose $[2,4,20]$. The drug is rated a category B drug during pregnancy. It should only be used in respiratory depression, systemic hypotension or unresponsiveness in a closely monitored setting during or after endoscopy. It should be administered during pregnancy in small, graded doses titrated to the desired effect. It should not be routinely administered after endoscopy during pregnancy,since one neonatal fatality has been attributed to its use [21]. Naloxone is contraindicated in pregnant patients who are dependent on narcotics because it can precipitate opiate withdrawal syndrome [22]. Flumazenil, a benzodiazepine antagonist, is used to reverse oversedation from benzodiazepines administered during endoscopy. It is rated a category $\mathrm{C}$ drug during pregnancy. The drug should only be used to reverse benzodiazepine overdose during pregnancy because its fetal risks are largely unknown, with only few case reports of use during pregnancy. Flumazenil overdose can cause maternal seizures, particularly when administrated to patients who are chronically habituated to benzodiazepines. This overdose can be prevented by careful and slow titration and administration of minimal dosage of benzodiazepines required for endoscopy. $[4,19,20,23]$. 


\section{Upper gastrointestinal endoscopy}

Although it would be ideal to postpone all endoscopic procedures until after delivery, pregnant patients can develop conditions that require urgent upper endoscopy. The most common indications for EGD in pregnant patients are significant or continued gastrointestinal hemorrhage, dysphagia and refractory nausea and vomiting (Table 4). In a multicenter retrospective study of 83 pregnant women on safety and clinical efficacy of EGD in pregnant patients; endoscopy indications included gastrointestinal bleeding, abdominal pain and vomiting in decreasing order [24]. The Mallory-Weiss tear was an important cause of upper gastrointestinal bleeding in $14 \%$ of patients, the peptic ulcer was also responsible for $14 \%$ of gastrointestinal bleeding in those patients which is significantly lower than the reported frequencies in non pregnant patients. The diagnostic yield for upper gastrointestinal bleeding was $95 \%$ and there was no cases of premature labour or congenital fetal malformation. Labor was not induced in any of the patients and $95 \%$ of the patients gave birth to healthy infants. The four fetal deaths in the study were in all high risk patients and were unrelated to EGD. The mean Apgar scores of live born infants were not significantly different than control groups.

In an other study conducted by Debby et al [25], 60 pregnant women underwent EGD for recurrent and intractable nausea and vomiting in their first trimester. In that study only 11 patients had the upper gastrointestinal bleeding, the other majority had only intractable nausea and vomiting. The diagnostic yield of EGD in those patients appeared higher for gastrointestinal bleeding than for intractable vomiting but the difference was not statistically significant. Since the endoscopic findings only minimally changed the clinical management of patients with nausea and vomiting the authors suggested the necessity of EGD for upper gastrointestinal bleeding but not nausea and vomiting or hyperemesis gravidarum. A mailed survey of over 3000 members of the American College of Gastroenterology, which included information over 73 upper endoscopies performed during pregnancy. Endoscopic diagnoses from these procedures included esophagitis, gastritis, ulcers, Mallory-Weis tears and normal findings in descending order. This survey reported no significant complications adversly affecting pregnancy [26].

The relationship between hyperemesis gravidarum and Helicabacter Pylori (H.Pylori) infection is estimated by Bagis et all, in their study, $\mathrm{H}$ Pylori infection was histologically demonstrated in $95 \%$ of pregnant patients with hyperemesis gravidarum and $50 \%$ of control patients. In that study patients with hyperemesis gravidarum had more severe H. Pylori infection compared to controls with H.Pylori infection, as measured histologically by density of bacterial infiltration. Authors suggested the usage of H.Pylori diagnostic tests to be part of hyperemesis gravidarum investigation [27]. Upper gastrointestinal complaints, especially nause and vomiting, are very common in pregnants. During pregnancy with the effect of progesteron and estrogen and with a lesser effect of motilin hormone the lower esophageal sphincter (LES) tone, gastric and intestinal motility decrease, causing gastroesophageal reflux disease (GERD) symptoms. As pregnancy progresses, the frequency of and intensity of GERD symptoms increase which is caused by gastrointestinal motility changes during pregnancy and with a small contribution of physical effects of gravid uterus [28,29]. So as a conclusion endoscopy is rarely helpful and rarely indicated for nausea and vomiting, or even 
hyperemesis gravidarum, during pregnancy. In the presence of significant upper gastrointestinal bleeding or severe nause and vomiting accompanied by abdominal pain or refractory to medical treatment or signs of gastroduedenal obstruction, EGD may be appropriate to exclude significant peptic ulcer, gastric outlet obstruction or to treat bleeding site. According to the results of studies endoscopically the pregnant women has lower rate of peptic ulcer diseases but higher rate of reflux esophagitis compared to non pregnant patients, and the diagnostic yield of EGD for upper gastrointestinal bleeding during pregnancy is similar to that of EGD performed for the same indication in the general population of about $95 \%$ [30].

Acute nonvariceal upper GI bleeding (NVUGB) is a common clinical emergency leading to 50-160 hospitalizations per 100000 adults. Mortality may be as high as $10-14 \%$, although this appears to be decreasing in many countries [31]. Endoscopy for the nonvariceal upper GI bleeding (NVUGB) allows assesment of the risk of rebleeding and enables therapeutic hemostasis that reduces bleeding, the need for surgery, and mortality. The largest analysis of pregnant women for NVUGB is conducted by Geoffrey et al [32] in a population based study including 1210 pregnant women with NVUGB and 6050 nonpregnant women with NVUGB. Mallory-Weis tear was the most common identified cause of NVUGB in pregnant women, in contrast peptic ulcer diesase and gastritis were the predominant etiologies for NVUGB in nonpregnant patients. Pregnant women were less likely to require blood transfusion and were less likely to present with hypovolemic shock compared to nonpregnant women. EGD was performed substantially less frequently in pregnant women compared with nonpregnant women. The proportion of EGD's that led to therapeutic intervention was similar between pregnant and nonpregnant women, $8.9 \%$ vs $7.2 \%$ respectively. The mean interval from admission to EGD was longer for pregnant women compared with nonpregnant women. There were no in-hospital deaths among pregnant women with NVUGB, the proportions of pregnant and nonpegnant women requiring surgery for upper GI bleeding were not statistically different. Average hospital lenght of stay was shorter among pregnant women compared with nonpregnant women. Although the rates of maternal mortality and fetal loss were well below $1 \%$ in both groups, fetal distress/complications were lower in the pregnant group admitted with NVUGB, as was premature delivery. It can be concluded as; it is quite appropriate to defer endoscopy in a significant proportion of cases, who remain hemodynamically stable with self-limited NVUGB.

The indications of endoscopy in pregnacy is shown in table 4 [2].

\begin{tabular}{ll}
\hline 1 & Significant or continued bleeding \\
\hline 2 & Severe or refractory nausea and vomiting or abdominal pain \\
\hline 4 & Dysphagia or odynophagia \\
\hline 5 & Strong suspicion of colon mass \\
\hline 6 & Severe diarrhea with negative evaluation \\
\hline 7 & Biliary pancreatitis, choledocholithiasis, or cholangitis \\
\hline
\end{tabular}

Table 4. Indications for endoscopy in pregnancy (ASGE) 


\section{Therapeutic endoscopy}

\subsection{Endoscopic hemostasis for variceal bleeding}

Patients with cirrhosis are not likely to become pregnant due to endocrine and metabolic imbalances. On the other hand, women with non-cirrhotic portal hypertension have normal fertility rates. The incidence of variceal bleeding during pregnancy may reach up to $45 \%$ with a mortality rate of $18-50 \%$ The variceal bleeding frequently occurs during the last two trimester of gestation. The possible explanation for the high severity of variceal bleeding in pregnancy seems to be related to the increase in water retention and cardiac output, typical of both pregnancy and cirrhosis. Women with esophageal varices or severe liver disease should be advised, in case of planning the pregnancy, about the high risk of both variceal bleeding and hepatic decompensation during pregnancy. Also patients who have esophageal varices should be informed about the benefits of $\beta$-adrenergic receptor antagonist therapy during pregnancy to reduce portal pressure.

Both endoscopic injectional sclerotheraphy (EIS) and endoscopic band ligation (EBL) either prophylactic or urgent seem to be safe procedures during pregnancy. When bleeding is not arrested endoscopically in cirrhotic patients, an emergency transjugular intrahepatic portosystemic shunt (TIPS) is indicated, but data regarding pregnant cirrhotic women are scarce [33-39]. Since there are only a few case reports regarding the treatment options for this clinical condition, the management of esophageal varices and their major life-threatining complication - hemorhage during pregnancy is still under evaluation. In the early 80's EIS was generally accepted as the first line treatment procedure for bleeding esophageal varices. Despite this fact, only few cases of EIS with conventional sclerosants (polidocanol, absolute alchocol, sodium tetradecyl sulphate) were reported during pregnancy $[36,38,39]$. There are no studies regarding the effect of the conventional sclerosants on the fetus published in the literature, although the procedure is considered safe and effective to control active variceal bleeding. Vasoactive drugs used to achieve hemostasis are contraindicated during pregnancy, since these (vasopressin and terlipressin) may induce labor or fetal malformations [36]. Recently EBL was reported as an effective treatment option for active variceal hemorrhage as well as prophylaxis of this severe complication during pregnancy [36-39].

In early 90's EBL has been proven effective in controlling active hemorrhage and in long term prevention of recurrent bleeding. There are several case reports that describe successful hemostasis without fetal complications $[40,41]$. When EBL is used there is no risk of migration of a toxic substance to placenta. Studies of EBL versus EST in nonpregnant patients have shown improved reduction in rebleeding and mortality with EBL [40,42]. But there are no studies directly comparing EBL to EST in pregnant patients.

In a study conducted by Aggarwal et al, 17 patients with noncirrhotic portal hypertension caused by extrahepatic portal vein obstruction or portal fibrosis, underwent EIS with either absolute alcohol or sodium tetradecyl sulphate for acute variceal bleeding without complications during pregnancy. In that retrospective analysis pregnancy outcomes included six healthy full-term infants, two preterm deliveries, three stillbirths, one neonatal death, and 
five voluntary abortions. In that report two patients required EBL after failure of EIS to obliterate esophageal varices [43].

In an another report 10 patients underwent EIS with absolute alcohol, 5 patients for active variceal bleeding and another 5 patients for the profilaxis of variceal bleeding. Hemostasis was achieved in 5 actively variceal bleeding patients. All 10 patients delivered healthy infants [44]. According to the reported studies as in the nonpregnant population, EBL seems to be a reasonable option for acute variceal bleeding as well as for the profilaxis of variceal bleeding. EIS could be a secondary choice for the acute variceal bleeding due to the probable effects on fetal safety.

When the endoscopic and pharmacological theraphy fails; TIPS may be a rescue procedure in pregnant women with recurrent and difficult-to treat variceal bleeding. Several papers confirm the utility and efficacy of TIPS for variceal bleeding unresponsive to endoscopic and pharmacological treatment, however since adequate controlled trials are lacking, it should be limited to a selected group of patients. TIPS placement is associated with radiation exposure of both the patient and the medical staff, it usually requires prolonged fluoroscopy. In the literature there is a few case of TIPS placement in pregnancy in which between $5.2 \mathrm{mSv}$ and $2.1 \mathrm{mGy}$ fetal dose of radiation reported $[35,45,46]$. So pregnancy is not an absolute contraindication for TIPS placement in the treatment of relapsing bleeding varices and may be a rescue procedure when medical and endoscopic treatments have failed.

\subsection{Endoscopic hemostasis for nonvariceal bleeding}

Endoscopic hemostatic techniques for nonvariceal bleeding include injection therapy with saline, with adrenaline, sclerosants, thrombin, fibrin, cyanoacrilate, ablative therapy with thermocoagulation, electrocoagulation, photocoagulation, argon plasma coagulation, and mechanical compression with hemoclips, detachable snares, graspers, or sutures [47]. In spite of these numerous techniques, there are a few case reports on fetal safety of endoscopic hemostasis for NVUGB. In those case reports adrenalin injection, thermocoagulation and electrocoagulation was used for hemostasis. In only one of the pregnant patient the hemostatic procedures were unsuccesful so patient required surgery. The fetal outcomes were healthy infants without fetal malformations [24,25,47,48,49].

Adrenalin is category $\mathrm{C}$ drug and can cause a decrease in uterine blood flow. Although there is limited data of case reports, no advers events from adrenaline injection were reported, in this case the benefits (cessation of hemorhage, prevention of rebleeding) would seem to outweigh the risks $[1,2,29,50]$.

Amniotic fluid can conduct electrical current to the fetus. During the electrocoagulation the grounding pad should be placed in such a position that the uterus is not between the electrical catheter and grounding pad. Bipolar electrocautery should be used to minimize the risk of 'stray' currents going through the fetus. Electrocautery is relatively safe when used for hemostasis[2]. Due to the limited data on hemostasis for nonvariceal bleeding in pregnant patients, the therapeutic technique choice is based on expert opinion and generally made according to the results of clinical studies of nonpregnant patients. 


\subsection{Percutaneous endoscopic gastrostomy}

During pregnancy, optimal nutrition is essential in order to minimize maternal and neonatal morbidity [51]. Nause and vomiting are seen in $80 \%$ of pregnancies but usually symptoms are mild and self limited. In case of severe hyperemesis gravidarum with dehydration and ketonuria, patients should be hospitalized and receive intravenous hydration and anti-emetic agents. When the hospitalization duration prolongs without oral intake then supportive nutrition with enteral feeding or total parenteral nutrition should be considereed [29]. Long term nasogastric feeding is limited by patient intolerability and nasal septal necrosis. Side effects of long term total parental nutrition limit its usage during pregnancy[52]. Thus percutaneous endoscopic gastrostomy (PEG) becomes an important option for long term enteral feeding. However, concerns about uterine damage, fetal injury, premature labor, and infections have restricted the application of PEG tube placement in pregnant women. There were no major complications with PEG tube placement in the several reported cases in the literature [53-61]. PEG enteral nutritional support was provided for an average of 14 weeks in the literature. During the pregnancy PEG tube placement is a feasible procedure for optimal enteral nutrition in the critical care setting. It is also feasible to perform PEG tube placement in the third trimester of pregnancy. A potential problem with PEG during pregnancy is puncture of uterus or fetus instead of the stomach during transabdominal neddle insertion. This risk is reduced by demarcating the upper border of uterus before PEG by abdominal ultrasonography and by inserting the PEG needle $\geq 5 \mathrm{~cm}$ cephaled.

PEG tube placement should be reserved only for severe refractory cases where the nutrition of the mother and the fetus is at risk. The pregnant should be informed about the risks of the procedure and potential placental injury. If possible less invasive alternative techniques as nasoenteric feeding tube or peripherally inserted catheter for parenteral nutrition should be attempted if this is not succesful or is refused by the patient, PEG tube placement should be considered.

\subsection{Percutaneous endoscopic gastrojejunostomy}

Percutaneous endoscopic gastrojejunostomy( PEGJ) is a feeding tube placement in to the jejenum via a gastrostomy. This placement enables food to be delivered more distally to decrease the sensation of nausea, vomiting and risk of aspiration. PEGJ indications are similar to PEG indications with additional risk of aspiration. In case of refractory nause and vomiting in the presence of PEG tube feeding, PEG tube can be converted to PEGJ. There are only few case reports of PEGJ for hyperemesis gravidarum and one patient with coma from massive stroke [62-65]. As in the PEG, PEGJ can be considered in very severe hyperemesis gravidarum refractory to medical treatment and the other noninvasive treatment modalities.

\section{Sigmoidoscopy/ colonoscopy}

Most pregnant patients are young, healthy women and the gestational period is only 40 weeks in duration, because of that; it is unusual for them to need flexible sigmoidoscopy or 
colonoscopy during pregnancy. Lower endoscopy should be avoided for weak indications during pregnancy and should be deferred until after the first trimester, or if possible, until the postpartum period [66].

Although flexible sigmoidoscopy will be sufficient for most pregnant women, colonoscopy may be required when there is life-threatening colonic bleeding and when a cause has not been established by sigmoidoscopy. In late pregnancy, patients should not be placed in the decubitus or prone position during colonoscopy. External abdominal pressure should generally be avoided; if pressure is required, it should be minimal and directed away from the uterus.

All avilable evidence suggests that sigmoidoscopy is safe during pregnancy and the indications include rectal bleeding, chronic diarrhea, abdominal pain and rectal pain. Guidelines for colonoscopy in pregnancy are not readily available due to insufficient data, although studies which have been done demonstrate safety and efficacy of the procedure provided that obstetrical consultation and close monitoring take place. Colonoscopy is indicated for suspected colon cancer, uncontrolled severe hemorrhage or when necessary before colonic surgery in pregnant women as well as in general population $[67,68]$.

The safety and efficacy of the flexible sigmoidoscopy during pregnancy has been studied in one case-controlled study of 45 patients undergoing 48 sigmoidoscopies [69]. The most common clinical indication was hematochezia in 29 patients, diarrhea was the indication in 10 patients and abdominal pain was in 4 patients. The most common sigmoidoscopic diagnosis included reactivated or newly diagnosed inflamatory bowel disease, bleeding internal hemorroids and other colitis. Among the 29 patients with hematochezia, 8 patients were de novo diagnosis or flare of ulcerative colitis, 7 patients were de novo diagnosis or flare of Crohn's disease, 3 patients with acute proctosigmoitidis, 2 patients were bleeding internal hemorrhoids, 1 patient was pseudomembraneous colitis, and 1 patient was sigmoid adenoma. Hematochezia gave the highest diagnostic yield compared with the other clinical indications. Excluding one unknown pregnancy outcome and four voluntary abortions, 38 (93\%) of 41 pregnant patients who underwent sigmoidoscopy delivered healthy infants, including 27 at term. The mean Apgar score of live-born infants in this study was not statistically different from the mean national Apgar score of live born infants.

Therapeutic changes because of the sigmoidoscopic findings occured in 24 patients, including changing or instituting medication for inflamatory bowel disease in 15 patients, steroid enemas for nonspesific proctitis in two patients, avoiding surgery in two patients, and hemorrhoidal treatment in two patients.

Other than this study there are individual case reports of sigmoidoscopy performed during pregnancy and a mailed survey study [26, 70-74]. Multiple case reports describing flexible sigmoidoscopy in pregnant patients showed the safety of this procedure. In the mailed survey study; after contacting 3300 gastroenterologists, their responses indicated that there were no endoscopic complications in 13 pregnant women who underwent flexible sigmoidoscopy. In addition all pregnancies resulted in healthy infants. Common themes among these reports include a relatively high diagnostic yield of flexible sigmoidoscopy when per- 
formed during pregnancy for strong indications, clinically important changes in therapy resulting from sigmoidoscopic diagnosis, a relatively high rate of favorable fetal outcomes, poor fetal outcomes generally occuring only in very sick mothers and unrelated to sigmoidoscopy etiologically or temporally, and a low rate of congenital anomalies.

Studies suggested that sigmoidoscopy during pregnancy does not induce labor or cause congenital malformations, it is not contraindicated, and should be considered in medically stable patients with important indications. Sigmoidoscopy should be performed with maternal monitoring by electrocardiography and pulse oximetry, after obstetrical consultation and after medical stabilization. Medical stabilization may require blood transfusions and supplemental oxygenation $[4,66,68]$. Sigmoidoscopy is not recommended during pregnancy for indications of a change in bowel habits, abdominal pain, a family history of colon cancer, and routine screening or surveillance. In these cases, sigmoidoscopy is best deferred until at least 6 weeks postpartum $[67,68]$.

Little is known about the safety or otherwise of bowel cleansing agents during pregnancy. Studies have shown that the systemic absorbtion of Polyethylene glycol is minimal and the problems with abdominal bloating and gas are less common as compared to other laxatives [75] But since polyethylene glycol solutions have not been studied during pregnancy, therefore it is a category $\mathrm{C}$ drug during pregnancy. Sodium phosphate solutions (also category C) may cause fluid and electrolyte disturbance, and therefore probably best avoided during pregnancy. Also it was published that newborns were shown to manifest bone demineralization and bone growth failure because of maternal phosphate overload [76], although a one time use in pregnancy has not shown to be detrimental. Another consideration when using phosphosoda preperations is the risk of phosphate nephropathy [77] which has been reported in selected cases. As for bowel preperation for flexible sigmoidoscopy, phosphate enemas should be relatively safe, but have not been studied in pregnancy. Tap water enemas may be sufficient. In a study [78] of the preference of gastroenterologist and obstetricians of bowel cleansing agent for sigmoidoscopy and colonoscopy in the same hospital, it was shown that $50 \%$ of gastroenterologist prefer to use polyethylene glycol solutions and $50 \%$ avoid use of fleet phosphosoda. Twent percent of obstetricians seem to prefer fleet phosphosoda, and $26 \%$ avoid polyethylene glycol solutions which is exact opposite of gastroenterologist. Both groups prefer fleet enema the most (51\%), while magnesium citrate is used least often $(38 \%)$.

\section{Colonoscopy}

There are insufficient data regarding the safety of performing colonoscopy during pregnancy. The largest case control study of 20 patients [79]; there were 20 pregnant patients undergoing colonoscopy and 20 pregnant controls who were matched for colonoscopy but who did not undergo colonoscopy. Colonoscopy indications in the study patients included diarrhea, hematochezia, bloody diarrhea, abdominal pain, and other reasons. Colonoscopy was performed in the second trimester in the majority of patients $(n=16)$ with only 4 patients undergoing the procedure in the first and third trimester. Colonoscopic diagnoses were; ulcer- 
ative colitis, ischemic colitis, Crohns colitis, and lymphocytic colitis. Colonoscopy led to significant therapeutic changes in 7 (35\%) patients. Two mothers experienced minor colonoscopic complications of mild, transient hypotension. Study patients had relatively favorable fetal outcomes: 18 relatively healthy infants, 1 involuntary abortion, and 1 infant born with a congenital defect (septum secundum cardiac defect).

In a mailed survey of 3300 gastroenterologists 13 colonoscopies were performed without complications [26]. This study was retrospective, and subject to biases relating to recall and dependence on voluntary reporting. In an other study Cappell and co workers [69] retrospectively examined eight pregnant women undergoing colonoscopies at 10 different medical centers. Excluding one elective abortion and one fetal demise unrelated to the colonoscopy occuring 4 months later, six healthy infants were born. There was no difference in outcomes based on the trimester during which colonoscopy was performed.

There are several case reports about colonoscopy during pregnancy [80-88], fetal outcomes after colonoscopy included 8 healthy babies, 2 stillbirth unrelated to the colonoscopy (in mothers with either metastatic colon cancer or massive lower gastrointestinal hemorrhage requiring emergency colonic surgery), and one unknown fetal outcome.

Given the limited data on its safety and the potential to cause significant adverse events, colonoscopy should be reserved to strong indications or life-threatining emergencies during second trimester. But in case of suspicion of colon cancer, evaluation of colonic mass or colonic stricture of unknown etiology, for severe uncontrolled colonic hemorrhages, for colonic pseudoobstruction when the alternative is surgical decompression and when required before urgent colonic surgery, colonoscopy should be considered even in the first and third trimester. Colonoscopy should generally be deferred in any trimester of pregnancy until after delivery for elective indications, such as surveillance for prior history of colon cancer or colonic polyps.

\section{Therapeutic colonoscopy}

Therapeutic colonoscopy includes hemostasis of lower gastrointestinal bleeding, colonoscopic polypectomy, and colonic stenting. As mentioned in the hemostasis for NVUGB section,injection therapy with saline, with adrenaline, sclerosants, thrombin, fibrin, cyanoacrilate, ablative therapy with thermocoagulation, electrocoagulation, photocoagulation, argon plasma coagulation, and mechanical compression with hemoclips, detachable snares, graspers, or sutures are used during lower gastrointestinal bleeding [47].

Epinephrine is commonly used to treat gastrointestinal bleeding and achieves hemostasis through its vasoconstrictive effects. There are numerous studies about the fetal safety of epinephrine administration during labor which established its fetal safety so it is commonly added to spinal epidural anesthesia. Although in the report of Briggs and colleagues' [10], there was no congenital defect in 35 infants with first trimester in utero exposure of epinephrine, there is a case report of fatal intracranial hemorrhage in an infant during child- 
birth after excessive in utero epinephrine [89]. Because of the epinephrine's $\alpha$ adrenergic effect of decreasing uterine blood flow, it is a category $\mathrm{C}$ during pregnancy and its dosage should be kept low during pregnancy.

Electrocautery is also another method of providing hemostasis during lower gastrointestinal bleeding, also used for performing polypectomy or hot biopsy. Using electrocautery to lesions may occasionally be required during pregnancy and has been safely performed without detectable advers effcts to fetus. However, because amniotic fluid has been demonstrated to conduct electrical current, externally placed grounding pad should be placed close to the electrical catheter, devices should use bipolar currents. Polyp removal if not bleeding, should be postponed after pregnancy $[4,5,66]$.

Colonic tattooing is done with Indian ink and methylene blue in nonpregnant patients. Indian ink has been shown to persist for the entire life of patient. There have ben no reports of long term complications of Indian ink tattooing. Methylene blue tattooing during pregnancy is not been studied but there are reports of examination of Metylene blue during amniocentesis and in detection of ruptured membranes. In these reports fetal death, jejunal atresia, is reported which labels Metylene blue as teratogenic. Although safety of colonic injection is not studied; its usage should be avoided during pregnancy [66, 90, 91].

\section{Enteroscopy}

Enteroscopy takes a very long time of procedure with a long time of anesthesia. There is no case report of enteroscopy during pregnancy, so the fetal safety of enteroscopy could not be predicted.

\section{Video capsule endoscopy}

Video capsule endoscopy (VCE) represents a significant advance in the investigation of small bowel diseases. The main indications are obscure gastrointestinal hemorrhages, Crohn's disease, celiac disease, small bowel tumors and polyposis syndromes. The main contraindications are known or suspected gastrointestinal obstruction, strictures, fistulas, cardiac pacemakers and swallowing disorders [92]. During pregnancy the growing gravid uterus pushes and compresses the gastrointestinal tract, and gastrointestinal motility decreases due to inhibition of intestinal smooth muscle by gestational progestin. These effects raise the theoretical concerns regarding capsule impaction during pregnancy [4,93]. Although according to the FDA, pregnancy is a relative contraindication for VCE [92]; there is a report of VCE usage in a young acute bleeding pregnant patient in whom endoscopy and colonoscopy revealed no lesion other than fresh blood exiting the terninal ileum. On VCE an actively bleeding jejunal lesion was shown of which pathology was jejunal carcinoid tumor. Patient and fetus did well after surgery [94]. From this report, it can be concluded that VCE may be considerable during pregnancy for strong indications, it is not absolutely contraindi- 
cated during pregnancy. But it is more likely to be incomplete when done during pregnancy because of slowed intestinal transit time during pregnancy.

\subsection{Endoscopic retrograde cholangiopancreatography}

Pregnancy is associated with an increased risk of gallstone formation. Fortunately, complications due to cholelithiasis, such as cholecystitis, choledocholithiasis and pancreatitis are relatively uncommon and in many cases can be managed conservatively. However occasionally patients develop complications related to gallstones that require intervention during pregnancy. Although there are no precise estimates of the incidence, several reports have found that biliary tract disease (most commonly cholecystitis) represented one of the most frequent indications for non-obstetrical surgery during pregnancy [95-99].

A subset of patients requires ERCP, most commonly for choledocholithiasis or presumed gallstone pancreatitis. Opinions regarding the safety of ERCP during pregnancy differ in various reports, reflecting the relatively limited data. Major concerns surround issues related to radiation exposure to the fetus and the risk of procedure on pregnancy outcome.

A general principle in the care of the women with an acute biliary tract disorder during pregnancy is to provide the most conservative management possible with the hope of delaying intervention until after pregancy or until the second trimester, when surgical intervention is relatively safer. There are numerous reports about ERCP during pregnancy especially for the last ten years.

The largest series in the literature included 65 pregnant patients [100]; the most common indications for ERCP during pregnancy were recurrent biliary colic, abnormal liver function tests, and a dilated bile duct on ultrasound. Sixty eight ERCP was performed on 65 pregnant patients, 17 pregnants were in the first trimester, 20 pregnants were in the second trimester and 31 pregnants were in the third trimester. The median fluoroscopy time was 1.45 minutes. Almost all patients underwent a therapeutic procedure. Post ERCP pancreatitis developed in 11 patients (16\%), none of whom had a severe course. Most patients achieved a term pregnancy $(89 \%)$, there were no fetal deaths, perinatal deaths, or evident congenital malformations. Only 5 babies (8\%) were born prematurely or with low birth weight.

Another series of 23 patients included 20 of whom underwent a therapeutic ERCP while three underwent a diagnostic ERCP only [101]. One patient developed post ERCP pancreatitis (after each of her three ERCP). There was one spontaneous abortion and one neonatal death 26 hours after delivery. The neonatal death and post-ERCP pancreatitis were in the same patient who undergone three ERCPs (twice during the first and one during the third trimesters) with pancreatic duct stenting for stenosis of pancretaic orifice after a previous surgical sphincteroplasty.

Shelton et al in a retrospective series of 21 cases of ERCP with sphincterotomy reported successful extraction of stones in 14 women and successful removal of sludge in 7 women. There was one maternal complication of pancreatitis. There were 17 healthy babies delivered at term; One preterm, low birth weight baby, and 3 unknown fetal outcomes [102]. 
Another series described long term follow up of 18 pregnant women who underwent biliary sphincterotomy for common bile duct stones during pregnancy (first trimester 4, second 6, third 8) [103]. Despite short term complications (one with postsphincterotomy bleedings, one with mild post ERCP pancreatitis and preterm labor), no long term maternal complications were seen after a median of six years (range 1-11 year). Only 11 of the 18 families were retrospectively contacted; all 11 babies were healthy on follow up at a mean of 6 years postpartum. Only one mother had preterm delivery.

Kahaleh et al reported a total of 17 pregnant patients underwent ERCP; of which 15 had radiation dosimetry measured. Mean fluoroscopy time was 14 seconds (1-48seconds), mean estimated fetal radiation exposure was 40mrad (1-180mrad). Complications were reported as; postsphincterotomy bleeding in one patient, which was controlled by placement of hemoclip, and post-ERCP pancreatitis in one patient. All infants delivered had Apgar scores of 8 or greater. Thirteen of 15 patients who delivered were contacted, and they confirmed that their child was in good health. [104].

In an another series of 15 patients, the incidence of complications (7\%) was no different than the rate of complications observed in nonpregnant patients. [105]. There were no serious adverse outcomes to the fetus or mother.

Different from the aforementioned reports, Farca et al reported a prospective study $\geq 10$ therapeutic ERCP during pregnancy [106]. In this study a single 10F stent was placed without sphincterotomy, all patients had uncomplicated pregnancies and delivered healthy infants. All underwent ERCP with sphincterotomy and stent extraction postpartum; 8 had stones extracted. In two patients, the single 10F stent remained in place for 7 and 8 months, respectively; no one developed cholangitis.

During the ERCP in pregnancy the perceived risk of radiation exposure is much greater than the actual risk, but a full explanation of these risks to the pregnant patient and her family is more credible if given prior to exposure. Patients should be fully informed, background population risks for miscarriage, congenital anomalies, genetic disease, and the growth restriction are approximately 20,4, 10 and 10 percent, respectively. Potential radiation exposure risks to the fetus can be divided into four categories: intrauterine fetal death, malformations, disturbance of growth and development, mutagenic and carcinogenic effects.

Ionizing radiation is measured in special units, rad (radiation absorbed dose) and rem (radiation equivalent man) and in the international units, gray (Gy) and sievert (Sv)

$(1 \mathrm{rad}=1 \mathrm{rem}=0.01 \mathrm{~Gy}=0.01 \mathrm{~Sv})$. The avarage person in United States receives about 360 mrem of ionizing radiation annually, of which about 60 mrem comes from man-made sources, including medical exposures such as diagnostic radiographs. The rem is a unit used to measure the effect of radiation on the human body is referred to as the ' effective dose equivalent'. Fetal radiation exposure can result in developmental abnormalities, particularly if exposure is during the first trimester when organogenesis occurs. High radiation exposure may result in fetal wastage. Although estimates vary, it is recommended that fetal radiation exposure not exceed 100mrem during the first trimester [104]. 
Data from studies of animals and nuclear bomb survivors suggest that the period of major organogenesis, between the 8th and 15th weeks of gestation, is the most sensitive for growth retardation, which may be observed with exposures of 200-250mrem. Exposures greater than 100mrem occuring later, during neuron development and migration, may be associated with microcephaly, seizures, decline in mental ability, and childhood cancer [107]. During the whole of gestation, the maxium permitted dose of ionizing radiation to the fetus is 500rems [108].

Lead shielding should be used to minimize radiation exposure to the uterus. The lead apron shield must be placed underneath the patient and not draped over the abdomen since the radiation source is underneath the patient when using the standard fluoroscopy C-arm [109]. External shielding can not elimineta fetal exposure due to internally scattered radiation. Even though the fetus can be shielded, efforts should be made to avoid performing ERCP during the first trimester. While harmful effects of radiation exposure are unlikely to develop below a certain threshold of radiation dose, the threshold associated with a risk of childhood cancers such as leucemia is not known precisely.

Though a majority of investigators have reported no immediate complication in newborn, because of low dose radiation exposure, no one has looked 10-20 years after the exposure, from that point; ERCP without fluoroscopy is investigated.

ERCP without fluoroscopy has been reported in some studies $[102,111]$ in the last years. Sharma and Maharshi [110] described a two step procedure with biliary sphincterotomy and stenting without fluoroscopy or ultrasound (US) asistance as a first step and definitive ERCP with stone extraction after delivery. In another series [102] it is described as; endoscopist controls wire -guided cannulation first; then the cannule is not advanced in to the duct unless the endoscopist is confident that the bile duct has been cannulated, as assesssed by the presence of bile flowing around the wire from the papillary orifice. Once biliary cannulation is confirmed, a standard wire-guided biliary sphincterotomy is performed using the papillotome. While the bile is not seen flowing around the guidewire, instead of advancing the catheter to aspirate fluid, a 5F $2 \mathrm{~cm}$ stent is inserted over the wire and the drainage from the stent is observed. The color of draining fluid is used to assess whether the stent is in the bile duct or the pancreatic duct. If the stent reveals bile flow, a stent -guided biliary sphincterotomy using a needdle-knife is performed. The stent is removed after biliary sphincterotomy.

Even though the introduction of ERCP without fluoroscopy, ERCP should be avoided for weak indications such as preoperative cholangiography in patients with a low probability of having choledocholithiasis. Women of childbearing age should be asked about the possibility of pregnancy and a pregnancy test should be ordered based on clinical history. Other methods of diagnosis that do not involve radiation should be considered, magnetic resonance cholangiopancreatography (MRCP) can provide diagnostic information for a variety of hepatobiliary conditions while endoscopic ultrasonography (EUS) is highly sensitive and spesific for choledocholithiasis. MRCP for the detection of common bile duct stone and subsequent extraction without using fluoroscopy has been reported in some newly published case reports. In a study conducted by Oto et al [111], the role of MRCP in the evaluation of pregnant patients with acute pancreaticobiliary disease is investigated; 18 pregnant patients 
underwent MRCP for the indications of right upper quadrant pain, cholangitis, jaundice and pancreatitis. Fifteen of the 18 patients were also evaluated with abdominal US. Biliary dilatation was detected in 8 patients with US, but the cause of biliary dilatation could not be determined by US in 7 patients. MRCP demonstrated the etiology in four of these patients (choledocholithiasis, Mirizzi syndrome, choledochal cysts, and intrahepatic biliary stones) and excluded obstructive pathology in the other four patients. MRCP was unremarkable in the 7 patients who had no biliary dilatation on US. Three patients underwent only MRCP; two had choledocholithiasis, and one had cholelithiasis and pancreatitis. While this study suggests that MRCP may be very helpful diagnostically for acute pancreatobiliary disease in the pregnant population, this study does not give any information about the fetal outcomes, including the incidence of congenital amlformations after MRCP during pregnancy.

So, in the case of choledocholithiasis, biliary pancreatitis, cholangitis and findings of coledochal dilatation on abdomianl US with abnormal serum liver function tests and known gallstones, ERCP with / without fluoroscopy should be made.

\subsection{Electrocautery and hemostasis}

Using cutting and cauterizing current to lesions may occasioanlly be required during pregnancy and has been safely performed without detectable adverse consequences to the developing fetus. However, because amniotic fluid has been demonstrated to conduct electrical current [112], a number of precautions are appropriate. These include ensuring that the externally placed graunding pad is placed close to the interventional electrical catheter so that the uterus does not lie between them. Devices using only bipolar currents should be used to minimize this risk of 'stray' currents going through the fetus. Electrocautery is relatively safe when used for sphincterotomy and hemostasis[2,5].

Epinephrine is category $\mathrm{C}$ drug during pregnancy and causes a decrease in uterine blood flow. Its safety, when used as an endoscopic injectant, has not been studied, although, when given in low dose combinations for analgesia, it is safe. Its use for hemostasis should balance the benefits with the potential risks [2].

\section{Endoscopic ultrasonography}

Endoscopic ultrasonography (EUS) is a widely accepted modality for the diagnosis of gastrointestinal and pancreatobiliary diseases. EUS has been shown to reduce unnecessary interventions in patients with low or moderate probabilities for choledocholithiasis. It is a safe alternative to fluoroscopy for the evaluation of biliary disorders during pregnancy. However, there are only case reports on EUS for pregnant patients in the literature. The largest series consist of 6 cases of EUS performed for suspected choledocholithiasis in pregnant patients [102]. EUS findings revealed choledocholithiasis in two patients, biliary sludge in two patients and nonsignificant findings in two patients.

All six patients were underwent ERCP after EUS, there were no maternal complications. Fetal outcome was favorable for 5 infants but one infant outcome was unknown. In another 
report, EUS was performed for acute pancreatitis of unknown etiology in 3 pregnant patients. Biliary pancreatitis without common bile duct stones found in 2 patients and pancreatitis due to unspecified pancreatic anomaly was found in one pregnant patient. There were no reported maternal complications in this study with 2 healthy infants but one fetal death 10 weeks after EUS probably due to recurrent cholangitis [113].

One may argue that EUS will prolong the overall time for a procedure. However, when EUS is normal, ERCP interventions can be avoided. In addition, EUS may provide other useful information. In experienced hands, the added time for EUS can be only a few minutes. So further studies are required to assess the role of EUS in the management of pregnant patients. However, it would seem acceptable to perform EUS when choledocholithiasis is a possible but unproven diagnosis and MRCP is an undesirable alternative.

\section{Endoscopic spyscopy}

The SpyGlass system is a recently developed system for performing cholangioscopy, pancreatoscopy. The main advantage over standard ERCP is that with the SpyGlass system the scope can be inserted directly into the bile duct and the pathology can be directly visualized, rather than using radiographs to visualize the bile ducts. This direct visualization allows the endoscopists to obtain a targetted biopsy, if needed, or to use electrohydraulic lithotripsy to crush stones under direct vision. This technique has been applied to 7 pregnant patients in the literature, five patients underwent choledochoscopy using spyscopy after ERCP, sphincterotomy, and balon sweeps; this procedure confirmed the removal of all choledochal stones in those patients. In one patient this technique is used to show residual $2 \mathrm{~mm}$ common bile duct stones after balon sweeping at ERCP, and in the remainig patient it has been used to show the sludge coming from the cystic duct. Choledochoscopy produced no maternal complications in those reports. This technique allows for the limitation or elimination of ionizing radiation through direct intraductal visualization and stone clearence confirmation. The diagnostic and therapeutic capability of ERCP is increased in a manner that contributes to patient safety and hopefully better maternal and fetal outcomes. So more studies are needed of this technique during pregnancy to asses the fetal outcomes [4, 114-116].

\section{Endoscopic cystogastrostomy}

Endoscopic cystogastrostomy with or without endosonographic guidance for drainage of pseudocyst has been demostrated to be an acceptable alternative to radiologic or surgical drainage. For the pregnant patient who has a pancreatic pseudocyst, this technique would be ideal because it would eliminate the risk of radiation incurred by a radiologic drainage and would involve less risk to the fetus than an intraabdominal surgical procedure. There are only two cases of endoscopic cystogastrostomy procedure applied to pregnant patients. In one patient it was successful; the pseudocyst was punctured percutaneously under con- 
ventional ultrasound guidance, than it is aspirated and filled with contrast agent. Then endoscopically a cystogastrostomy was created and a stent was inserted. The patient got well and gave birth to a healthy infant. In the second patient unfortunately the stent was migrated making the procedure partially unsuccessful, but with other techniques patient again got well and gave birth to a healthy infant too. So according to these two cases endoscopic cystogastrostomy is still a little bit experimental during pregnancy, it should be considered in pregnants who have symptomatic pseudocysts and cannot delay the procedure until delivery $[4,29,116-118]$.

\section{Author details}

Nurten Akyurek Savas

Baskent University, Department of Gastroenterology, Istanbul Hospital, Turkey

\section{References}

[1] O’Mahony S. Endoscopy in pregnancy. Best Practice \& Research Clinic Gastroenterol. 2007; 21 (5): 893-9.

[2] ASGE Guideline: guidelines for endoscopy in pregnant and lactating women Gastrointest Endoscopy 2005; 61 (3):357-62.

[3] Kammerer WS. Non-obstetric surgery during pregnancy. Med Clin North Am 1979; 63: 1157-64.

[4] Cappell MS. Risks versus benefits of gasrointestinal endoscopy during pregnancy. Nat Rev Gastroenterol Hepatol 2011; 8: 610-34.

[5] 5.Gilinsky NH, Muthunayagam N. Gastrointestinal endoscopy in pregnant and lactating women: Emerging Standard of care to guide decision-making. Obstet and Gynecol Survey 2006;61: 791-9.

[6] Glosten B. Anesthesia for Obstetrics. Miller RD (ed) Anesthesia Churchill Livingstone. New York. 2000; 2025-68.

[7] Morgan GE, Mikhail SM, Murray JM. Clinical anesthesiology . McGrow-hill, New York 2000; 819-46.

[8] Food and Drug Administration. Federal Register 1980; 44: 37434-67

[9] Jiraki K. Lethal effects of normeperidine. Am J Forensic Med. Pathol. 1992; 13(1): $42-3$. 
[10] 10. Briggs GC, Freeman RK, Yaffe SJ. Drugs in pregnancy and lactation: a reference guide to fetal and maternal risks, 8th edn (Lippincott, Williams \& Wilkins, Philadelphia, 2008)

[11] Rothman KJ, Fyler DC, Goldblatt A, Kreidberg MB. Exogenous hormones and other drug exposures of children with congenital heart disease. Am J Epidemiol 1979; 109: 433-9.

[12] Ornoy A, Arnon J, Shechtman S, Moerman L, Lukashova I. Is benzodiazepine use during pregnancy really teratogenic? Reprod Toxicol. 1998; 12: 511-5.

[13] Czeizel A. Lack of evidence of teratogenicity of benzodiazepine drugs in Hungary. Reprod. Toxicol. 1987; 1(3): 183-8.

[14] Laegreid L, Olegard R, Walström J\& Conradi N. Teratogenic effects of benzodiazepine use during pregnancy. J Pediatr. 1989; 114: 126-31.

[15] Arduini D, Rizzo G, Dell'Acqua S, Mancuso S, Romanini C. Effect of naloxone on fetal behavior near term. Am J Obstet Gynecol. 1987; 156: 474-8.

[16] Bland BA, Lawest EG, Duncan PW, Wanell I, Downing JW Comparison of midazolam and thiopental for rapid sequence anesthetic induction for elective cesarean section. Anesth Analg. 1987; 66(11): 1165-8.

[17] Ravlo O, Carl P, Crawford ME et al. A randomized comparison between midazolam and thiopental for elective cesarean section anesthesia: II. Neonates Anesth Analg. $1989,68,234-7$.

[18] Lazzaroni M, Bianchi Porro G. Preparation, premedication, and surveillance. Endoscopy 2005; 37 (2): 101-9.

[19] Cappell MS. Sedation and analgesia for gastrointestinal endoscopy during pregnancy. Gastrointest Endosc Clin N Am 2006; 16: 1-31.

[20] Fassoulaki A, Theodoraki K, Melemeni A. Pharmacology of sedation agents and reversal agents. Digestion 2010; 82: 80-3.

[21] Goodlin R.C. Naloxone and its possible relationship to fetal endorphin levels and fetal distress. Am J Obstet Gynecol. 1981; 139: 16-9.

[22] Gibbs J, Newson T, Williams J, Davidson D.C. Naloxone hazard in infant of opioid abuser. Lancet. 1989; 2 (8655): 159-160.

[23] Brogden RN, Goa KL. Flumazenil. A reappraisal of its pharmacological properties and therapeutic efficacy as a benzodiazepine antagonist. Drugs1991; 42:1061-89.

[24] Cappell MS, Colon VJ, Sidhom O A. A study at eight medical centers of the safety and clinical efficacy of esophagogastroduedenoscopy in 83 pregnant females with follow-up of fetal outcome and with comparison to control groups. Am J Gastroenterol 1996; 91: 348-54. 
[25] Debby A, Golan A, Sadan O, Glezerman M, Shirin H. Clinical utility of esophagogastroduodenoscopy in the management of recurrent and intractable vomiting in pregnancy. J Reprod Med. 2008; 53: 347-51.

[26] Frank B. Endoscopy in pregnancy. In: Karlstadt RG, Surawicz CM, Croitoru R., editors. Gastrointestinal disorders during pregnancy. Arlington, VA: American College of Gastroenterology:1994. 24-9.

[27] Bagis T, Gumurdulu Y, Kayaselcuk F, et al. Endoscopy in hyperemesis gravidarum and Helicobacter pyleri infection. Int J Gynacol Obstetr 2002; 79:105-9.

[28] Baron TH, Ramirez B, Richter JE. Gastrointestinal motility disorders during pregnancy. Ann Intern Med 1993;118 (5):366-75.

[29] Bruno JM, Kroser J. Efficacy and safety of upper endoscopy procedures during pregnancy Gastrointest Endoscopy Clin N Am 2006; 16: 33-40.

[30] Chak A, Cooper GS, Lloyd LE, et all. Effectiveness of endoscopy in patients admitted to the intensive care unit with upper GI hemorrhage. Gastrointest Endosc. 2001; 53:6-13.

[31] Barkun AN, Bardou M, Kuipers EJ, et al. International consensus recommendations on the management of patients with nonvariceal upper gastrointestinal bleeding. Ann Intern Med 2010; 152(2): 101-13.

[32] Nguyen GC, Dinani AM, Pivovarov K. Endoscopic management and outcomes of pregnant women hospitalized for nonvariceal upper GI bleeding: a nationwide analysis. Gastrointest Endoscopy 2010; 72: 954-9.

[33] Russell MA, Craigo SD. Cirrhosis and portal hypertension in pregnancy. Semin perinatol 1998; 22: 156-65.

[34] Homburg R, Bayer I, Lurie B. Bleeding esophageal varices in pregnancy. A report of two cases. J. Reprod Med 1988, 33: 784-6.

[35] Lodato F, Cappelli A, Montagnani M, et al. Transjugular intrahepatic portosystemic shunt: A case report of rescue management of unrestrainable variceal bleeding in a pregnant woman. Digestive and Liver Dis 2008; 40: 387-90.

[36] Starkel P, Horsmans Y, Geubel A. Endoscopic band ligation: a safe technique to control bleeding esophageal varices in pregnancy. Gastrointest Endosc 1998; 48: 212-4.

[37] Dhiman RK, Biswas R, Aggarwal N, Sawhney H, Chawla Y. Management of variceal bleeding with endoscopic variceal ligation and N-butyl-2 cyanoacrylate: report of these cases. Gastrointest Endosc 2000; 51: 91-3.

[38] Iwase H, Morise K, Kawase T, Horiuchi Y. Endoscopic injection sclerotherapy for esophageal varices during pregnancy. J. Clin Gastroenterol 1994; 18: 80-3.

[39] Ghidirim G, Mishin I, Dolghii A, Lupashcu A. Prophylactic endoscopic band ligation of esophageal varices during pregnancy. J Gastrointestin Liver D. 2008;17: 236-7. 
[40] Stiegmann GV, Goff JS, Michaletz-Onady PA, ET AL.. Endoscopic sclerotherapy as compared with endoscopic ligation for bleeding esophageal varices. N eng J Med 1992; 326: 1527-32.

[41] Gimson AE, Ramage JK, Panos MZ, et al. Randomised trial of variceal banding ligation versus injection sclerotherapy for bleeding esophageal varices. Lancet 1993; 342: 391-4.

[42] de la Pena J, Rivero M, Sanchez E, etal. Variceal ligation compared with endoscopic sclerotherapy for variceal hemorrhage: prospective randomized trial. Gastrointest Endosc 1999; 49: 417-23.

[43] Aggarwal N, Sawhney H, Vasishta K, Dhiman RK, Chawla Y. Non-cirrhotic portal hypertension in pregnancy. Int J Gynaecol Obstet. 2001; 72: 1-7.

[44] Kochhar R, Kuma S, Goel RC., et al. Pregnancy and its outcome in patients with noncirrhotic portal hypertension. Dig Dis Sci 1999; 44:1356-61.

[45] Sanyal AJ, Freedman AM, Luketic VA, et al. Transjugular intrahepatic portosystemic shunts for patients with active variceal hemorrhage unresponsive to sclerotherapy. Gastroenterolgy 1996; 111: 138-46.

[46] Tesdal IK, Filser T, Weiss C, et al. Transjugular intrahepatic portosystemic shunts: adjunctive embolotherapy of gastroesophageal collateral vessels in the prevention of variceal rebleeding. Radiology 2005; 236: 360-7.

[47] Cappell MS. Therapeutic endoscopy for acute upper gastrointestinal bleeding. Nat Rev Gastroenterol Hepatol. 2010; 7: 214-29.

[48] Brunner G, Meyer H, Athmann C. Omeprazole for peptic ulcer disease in pregnancy. Digestion 1998; 59; 651-4.

[49] Macedo G, Carvalho L, Ribeiro T. Endoscopic sclerotherapy for upper gastrointestinal bleeding due to Mallory-Weiss syndrome. Am J Gastroenterol. 1995; 90, 1364-5.

[50] Marcus MA, Vertommen JD, Van Aken H, Wouters PF. Hemodynamic effects of intravenous isoproterenol versus epinephrine in the chronic maternal-fetal sheep preperation. Anesth Analg 1996; 82: 1023-6.

[51] Villar J, Merialdi M, Gülmezoğlu AM, et al. Nutritional interventions during pregnancy for the prevention or treatment of maternal morbidity and preterm delivery: an overview of randomized controlled trials. J Nutr 2003; 133: 1606-25.

[52] Wong M, Apodaca CC, Markenson MG, Yancey M. Nutrition management in a pregnant comatose patient. Nutr Clin Pract.1997; 12: 63-6.

[53] Koh ML, Lipkin EW. Nutrition support of a pregnant comatose patient via percutaneous endoscopic gastrostomy. JPEN J Parenter Enteral Nutr 1993; 17: 384-7.

[54] Shaheen NJ, Crosby MA, Grimm IS, Isaacs K. The use of percutaneous endoscopic gastrostomy in pregnancy. Gastrointest Endosc 1997; 46: 564-5. 
[55] Godil A, Chen YK. Percutaneous endoscopic gastrostomy for nutrition support in pregnancy associated with hyperemesis gravidarum and anorexia nervosa. JPEN J Parenter Enteral Nutr 1998; 22: 238-41.

[56] Serrano P, Velloso A, Garcia-Luna PP, et al. Enteral nutrition by percutaneous endoscopic gastrojejunostomy in severe hyperemesis gravidarum: a report of two cases. Clin Nutr 1998; 17: 135-9.

[57] O'Connell MP, Wilson OF, Masson EA, Lindow SW. Pregnancy outcome in a patient with chronic malnutrition. Hum Reprod 2000; 15: 2443-5.

[58] Wejda BU, Soennichsen B, Huchzermeyer H et al. Successful jejunal nutrition therapy in a pregnant patient with apallic syndrome. Clin Nutr 2003; 22: 209-11.

[59] Irwing PM, Howell RJ, Shidrawi RG. Percutaneous endoscopic gastrostomy with a jejunal port for severe hyperemesis gravidarum. Eur J Gastroenterol Hepatol 2004, 16: 937-9.

[60] Ceccaldi PF, Bazin A, Gomis P, et al. Persistent vegatative state with encephalitis in a pregnant woman with successful fetal outcome. BJOG. 2005 ; 112(6): 843-4.

[61] Senadhi V, Chaudhary J, Dutta S. Percutaneous endoscopic gastrostomy placement during pregnancy in the critical care setting. Endoscopy 2010; 42: E358-359.

[62] Pereira JL Velloso A, Parejo J, et al. Percutaneous endoscopic gastrostomy and gastrojejunostomy. Experience and its role in domiciliary enteral nutrition. Nutr Hosp $1998 ; 13: 50-56$. .

[63] Saha S, Loranger D, Pricolo V, Degli-Esposti S. Feding jejunostomy for the treatment of severe hyperemesis gravidarum: a case series. JPEN J Parenter Enteral Nutr. 2009 33(5):529-34. .

[64] Belda O, Serrano P, Bozada JM, et aI. Percutaneous endoscopic gastrostomy. Reality in the intra and extra community clinical nutritional practice. Rev Clin Esp 2005; 205: $472-7$

[65] Schrag SP, Sharma R, Jaik NP, et al. Complications related to percutaneous endoscopic gastrostomy (PEG) tube. A comprehensive clinical review. J Gastrointestine Liver Dis 2007; 16: 407-18.

[66] Siddiqui U, Proctor D.D. Flexible sigmoidoscopy and colonoscopy during pregnancy. Gastrointest Endoscopy Clin N Am. 2006; 16: 59-9.

[67] Cappell MS, Sidhom O. Multicenter, multiyear study of safety and efficacy of flexible sigmoidoscopy during pregnancy in 24 females with follow-up fetal outcome. Dig Dis Sci 1995; 40: 472-9.

[68] Cappell MS. The fetal safety and clinical efficacy of gastrointestinal endoscopy during pregnancy Gastroenterol Clin North Am 2003; 32: 123-179.

[69] Cappell MS, Colon VJ, Sidhom OA A study at 10 medical centers of the safety and efficacy of 48 flexible sigmoidoscopies and 8 colonoscopies during pregnancy with 
follow up of fetal outcome and with comparison to control groups. Dig Dis Sci 1996; 41:2353-61.

[70] Huang WS, Lin PY, Wang JY, Chin CC, Hsieh CC. Urgent colectomy and cesarean section of a pregnant familial adenomatous polyposis: a case report. Int J Colorectal Dis 2007; 22: 847-8.

[71] Ishijima N, Ojima E, Tonouchi H, Suzuki H, Fukunishi S. Delivery of a normal newborn after intensive medical treatment for an acute exacerbation of ulcerative colitis during pregnancy; a case report. Surg Today 1999; 29:1257-9.

[72] Minter A, Malik R, Ledbetter L, et al. Colon cancer in pregnancy. Cancer control 2005; 12: 196-202.

[73] Mirza M S, Mulla M., Hall RI, Large bowel obstruction in pregnancy: a rare entity, an unusual case. Arch. Gynecol. Obstet.2009; 279: 171-178.

[74] Seubert DE, Puder K, Goldmeier P, Gonik B. Colonoscopic release of the incarcerated gravid uterus. Obstet. Gynecol. 1999; 94: 792-4.

[75] Prather CM. Pregnancy-related constipation. Curr Gastroenterol Rep 2004; 6: 402-4.

[76] Rimensberger P, Schubiger G, Willi U. Connatal rickets following repeated administration of phosphate enemas in pregnancy: a case report. Eur J. Pediatr 1992; 151: $54-6$.

[77] Desmeules S, Bergeron MJ, Isenring P. Acute phosphate nephropathy and renal failure. N Eng J Med 2003; 349: 1006-7.

[78] Vinod J, Bonheur J, Korelitz BI, Panagopoulos G. Choice of laxatives and colonoscopic preperation in pregnant patients from the viewpoint of obstetricians and gastroenterolgists. World J Gastroenterol 2007; 13 (48): 6549-6552.

[79] Cappell MS, Fox SR, Gorrepati N. Safety and efficacy of colonoscopy during pregnancy: an analysis of pregnancy outcome in 20 patients. J Reprod Med 2010; 55: 115-23.

[80] Bashir RM, Montgomery EA, Gupta PK, et al. Massive gastrointestinal hemorrhage during pregnancy caused by ectopic decidua of the terminal ileum and colon. Am J Gastroenterol 1995; 90: 1325-7.

[81] Gonsoulin W, Mason B,Carpenter RJ. Colon cancer in pregnancy with elevated maternal serum alpha-fetoprotein level at presentation. Am J Obstet Gynecol. 1990; 163: 1172-3.

[82] Rojansky, N. Shushan A, Livni N, et al. Pregnancy associated with colon carcinoma overexpressing p53. Gynecol. Oncol. 1997; 64: 516-20.

[83] Van Voorhis, B, Cruikshank, D P. Colon carcinoma complicating pregnancy. A report of two cases. J Reprod Med. 1989; 34: 923-7. 
[84] Woods, JB, Martin JN, Ingram FH, et al. Pregnancy complicated by carcinoma of the colon above the rectum. Am J Perinatol. 1992; 9: 102-10.

[85] Chan, YM, Ngai SW, Lao T T Colon cancer in pregnancy. A case report. J Reprod Med. 1999; 44: 733-6.

[86] Montes H, Wolf J. Cecal volvulus in pregnancy. Am J Gastroenterol. 1999; 94: 2554-6.

[87] Rausch, ME, Troiano NH, Rosen T. Use of neostigmine to relieve a suspected colonic pseudoobstruction in pregnancy. J Perinatol. 2007; 27, 244-6.

[88] Rozen, P., Schreiber, L. \& Brazowski, E. Endometriosis, pregnancy, and colonoscopy. Endoscopy 2003; 35: 975

[89] Entmann SS, Moise KJ. Anaphylaxis in pregnancy. South Med J.1984; 77: 402.

[90] Kidd SA, Lancaster PA, Anderson JC, et al. A cohort study of pregnancy outcomes after amniocentesis in twin pregnancy. Pediatr Perinat Epidemiol 1997; 11: 200-13.

[91] Cragan JD. Teratogen update: metylene blue. Teratology 1999; 60: 42-8.

[92] Waterman M, Eliakim R. Capsule enteroscopy of the small intestine. Abdom Imaging 2009; 34: 452-8.

[93] Lawson M, Kern F, Jr, Everson GT. Gastrointestinal transit time in human pregnancy: prolongation in the second and third trimesters followed by postpartum normalization. Gastroenterology 1985; 89: 996-9.

[94] Hogan RB, Ahmad N, Hogan RBIII, et al. Video capsule endoscopy detection of jejunal carcinoid in life threatening hemorrhage, first trimester pregnancy Gastrointest Endosc 2007; 66: 205-7.

[95] Glenn F, McSherry CK. Gallstones and pregnancy among 300 young women treated by cholecystectomy. Surg Gynecol Obstet 1968; 127: 1067-72.

[96] Printen KJ, Ott RA. Cholecystectomy during pregnancy. Am Surg 1978; 44: 432-4.

[97] Amos JD, Schorr SJ, Norman PF, et al. Laparoscopic surgery during pregnancy. Am J Surg 1996; 171: 435-7.

[98] Curet MJ, Allen D, Josloff RK, et al. Laparoscopy during pregnancy. Arch Surg 1996; 131: 546-50.

[99] Graham G, Baxi L, Tharakan T. Laparoscopic cholecystectomy during pregnancy: a case series and review of the literature. Obstet Gynecol Surv. 1998; 53: 566-74.

[100] Tang SJ, Mayo MJ, Rodriguez -Frias E, et al. Safety and utility of ERCP during pregnancy. Gastrointest Endosc 2009; 69: 453-61.

[101] Jamidar PA, Beck GJ, Hoffman BJ, et al. Endoscopic retrograde cholangiopancreatography in pregnancy. Am J Gastroenterol 1995; 90: 1263-7. 
[102] Shelton J, Linder JD, Rivera-Alsina M. E., Tarnasky P.R. Commitment, confirmation, and clearence: new techniques for nonradiation ERCP during pregnancy. Gastrointest. Endosc. 2008; 67: 364-368.

[103] Gupta R, Tandan M, Lakhtakia S, et al. Safety of therapeutic ERCP in pregnancy-an indian experience. Indian J Gastroenterol 2005; 24: 161-3.

[104] Kahaleh M, Hartwell GD, Arseneau KO, et al. Safety and efficacy of ERCP in pregnancy. Gastrointest Endosc. 2004; 60: 287-292.

[105] Tham TC, Vandervoort J, Wong RC, et al. Safety of ERCP in pregnancy. Am JGastroenterol 2003; 98: 308-11.

[106] Farca A, Aguilar ME, Rodriquez G, de la Mora G., Arango L. Biliary stents as temporary treatment for choledocholithiasis in pregnant patients. Gastrointest. Endosc. 1997; 46: 99-101.

[107] Wagner L, Lester R, Saldana L. Exposure of the pregnant patient to diagnostic radiations: a guide to medical management. 2nd ed. Madison (WI): medical Physics Publishing. 1997.

[108] Campbell N, Sparrow K, Fortier M, Ponich T. Practical radiation safety and protection for the endoscopist during ERCP. Gastrointest. Endosc 2002; 55: 552-7.

[109] Barthel JS, Chowdhury T, Miedema BW. Endoscopic sphincterotomy for the treatment of gallstone pancreatitis during pregnancy. Surg Endosc 1998; 12: 394-9.

[110] Shelton J, Linder JD, Rivera Alsina ME, Tarnasky PR. Commitment, confirmation, and clearence: new techniques for nonradiation ERCP during pregnancy. Gastrintest Endosc 2008; 67: 364 .

[111] Oto A, Ernst R, Ghulmiyyah L, et al. The role of MR cholangiopancreatography in the evaluation of pregnant patients with acute pancreatobiliary diesase. The Br J Radiol. 2009; 82: 279-85.

[112] Einarson A, Bailey B, Inocencion G, et al. Accidental electric shock in pregnancy; a prospective cohort study. Am J Obstet Gynecol 1997; 176: 678-81.

[113] Roumieu F, Ponchon T, Audra P, Gaucherand P. Acute pancreatitis in pregnancy: place of the different explorations (magnetic resonance cholangiopancreatography, endoscopic ultrasonography) and their therapeutic consequences. Eur J Obstet Gynecol Reprod Biol 2008; 140: 141-2.

[114] Draganov P. The SpyGlass Direct Visualization system for cholangioscopy. Gastroenterol \& Hepatol 2008; 4: 469-70.

[115] Uradomo L, Pandolfe F, Aragon G, Borum ML. SpyGlass cholangioscopy for management of choledocholithiasis during pregnancy. Hepatobiliary Pancreat Dis Int 2011; 10: 107-8. 
[116] Girotra M, Jani N. Role of endoscopic ultrasound / SpyScope in diagnosis and treatment of choledocholithiasis in pregnancy. World J Gastroenterol 2010; 16: 3601-2.

[117] Ryan ME. Endoscopic management of a pancretaic pseudocyst during pregnancy. Gastrointest Endosc 1992; 38: 605-8.

[118] Gyokores T, Topa L, Marton I, Pap A. Endoscopic cystogastrostomy during pregnancy. Gastrointest Endosc 2001; 53: 516-8. 